\title{
Each Clubfoot is Different, Mother of All Clubfoot Innovations (An Incredible Unity in Diversity, with Cure-All, Fusion 4-in-1 Surgical Concept)
}

\author{
Mittal RL*
}

Consultant- Mittal Ortho Centre, 97 New Lal Bagh Colony, Patiala (Punjab) 147001, INDIA Emeritus Professor Orthopaedics, GOMCO Patiala

ISSN: 2576-8875

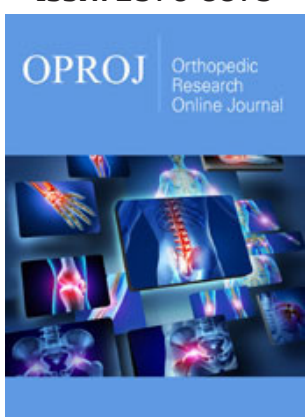

*Corresponding author: Mittal RL, Emeritus Professor, Orthopaedic Department, Government Medical College Patiala, India

Submission: 非 May 12, 2020

Published: 鲇 May 26, 2020

Volume 7 - Issue 1

How to cite this article: Mittal RL Each Clubfoot is Different, Mother of All Clubfoot Innovations (An Incredible Unity in Diversity, with Cure-All, Fusion 4-in-1 Surgical Concept). Ortho Res Online J. 7(1). OPROJ. 000655. 2020.

DOI: 10.31031/OPROJ.2020.07.000655

Copyright@: Mittal RL, This article is distributed under the terms of the Creative Commons Attribution 4.0 International License, which permits unrestricted use and redistribution provided that the original author and source are credited.

\begin{abstract}
Background: Author published a comprehensive research article on trimorphic extreme clubfoot deformities [1], offering, all-inclusive, triple/ quadruple surgical techniques, a far reaching solution, which received tremendous Global attention. This generic name (trimorphic extreme clubfoot deformities) was given, by the author, to scores of brand names in literature, reporting $95 \%$ failures post-surgeries with contemporary techniques. "Each Clubfoot Is Different" an important discovery therein, was prominently considered, for grading of results, rather than the prevalent assessment criteria of Pirani's or Demiglio's etc. Additional thoughts on this were recorded in author's invited BOOK on CLUBFOOT, published by Taylor and Francis (Informa group London U.K), ISBN: 9781138083738, released on 29th November, 2018 IOACON at Coimbatore (India). Author also performed, here, a Hat Trick, in clubfoot research, getting third best IOA original research award i.e. Diamond jubilee also; Golden and Silver awards bagged earlier in 2013 and 1988 respectively. During last about two years, as per its name, this research made significant headway with countless new features. Therefore, this has been christened as "Mother of all clubfoot discoveries/inventions", with its deep seated roots and incredible unity in diversity in its Allinclusive, corrective, 4-in-1, surgical concept. Being so and with its unending future research potential, it needs to be free from the lockdown of Journal and B00K, to spread awareness for the welfare of poor clubfoot community in LMICs, having more than $80 \%$ global population.
\end{abstract}

Methods: Recently conceived new features are: Firstly, formulating a comprehensive classification under numerous broad headings: Limitless variations in deformity start at birth; get modified with age, patient's weight, weight bearing, physical activity, treatments, early/ delayed complications, radiological variations etc. Secondly, the landmark, revelation in Rediscovery of Octopus Clubfoot, DOI: 10.31031/ OPROJ.2019.06.000627 and stamping its surgical correction as all-inclusive, branded, surgical concept; A Unity in Diversity. This was proved earlier by actually showcasing innumerable diverse deformities with gratifying results in author's International Orthopaedics as well as BOOK publications. This has been further strengthened with more new cases in this article (Table 1). Thirdly, many newer surgical steps have been added in the surgical corrections of these cases in the appropriate section in this article.

Results and Conclusion: This MASTERSTROKE article, a GRASSROOTS DISCOVERY, needs to spread awareness for an impactful message, giving a far better deal to poor Clubfoot community of LMICs, at lesser cost, with longer, good looking, better functioning feet, on long term, without any bony fusion and improving the patient's psycho-physico-socio-economics, helping indirectly their countries economy. The research in this entity is unending, each being different, therefore increasing awareness highly important. This will increase the demand for these surgeries and thereby a need for learning these comprehensive techniques through available internet channels and setting things going.

Keywords: Mother of clubfoot innovations; "Each clubfoot is different"; Extreme clubfoot deformities; Fusion 4-in-1 surgical concept; Octopus clubfoot rediscovered; Unity in diversity; Triple/ Quadruple surgical skin expansion; Cosmetic/Plastic surgery in clubfoot; Rozy feet

Abbreviations: AGMC: Arthrogryposis Multiplex Congenita; CCBs: Congenital Constriction Bands; CPC: Conjoint Posterior Capsule, DALYs: Disability Adjusted Life Years; DL: Dorsolateral; DOLAR: DOrsoLateral Rotation; EQ: Equinus; FDP: Flexor Digitorum Longus; FHL: Flexor Hallucis Longus; GBD: Global Burden of Disease; IOA: Indian Orthopaedic Association; IOACON: IOA Conference; IT: Intertarsal; ITC: Interosseous Talo-Calcanean; OA: Osteoarthritis; PMPDLR: Posteromedial Plantar Dorsal Lateral Release; TMT: Tarsometarsal

Introduction

"Each Clubfoot is Different" is the Mother of all Clubfoot inventions/ discoveries. It is like a ROSARY of countless beads, unified by its, 4-in-1, surgical concept. Author published in 2018, an original research article [1], Doi.10.1007/s00264-017-3741-6, receiving tremendous positive 
Global response. This research had been carried out in trimorphic deformities (a new name), with its equally matchless, infallible, surgical solution. To recapitulate 2018 article briefly, clubfoot remained unsolved, in spite of vast literature, with high prevalence rate of $95 \%$ failures, in neglected deformities with scores of brand names and no acceptable surgical solution [2-4]. Author researched this grey area in, need based, three phases, clustering all such brand names as trimorphic extreme deformities (three hierarchic grades), with an aim to improve upon contemporary surgical techniques. Posteromedial 3D skin contractures, in increasing severity, were discovered as the reasons for universal failures, which were corrected by all-inclusive, innovative, graded, expansion of fasciocutaneous chamber for increasingly severe/ rigid deformities.

First phase, in two stages, was the longest and continued for 2530 years, including years of building a strong foundation of critical analysis of prevalent failures in literature. $1^{\text {st }}$ stage was study of patho-anatomy, in 15 clubfeet of stillborn foetuses, published 1981 [5], discovering skin contracture as primary cause, reinforced by years of clinical observations. Second stage was a successful clinical study of 100, grade 1, extreme deformities, treated by DOrso Lateral Rotation skin flap (DOLAR technique - an acronym) 1987 [6].

Second phase continued for about 10-15 years, in grade 2 deformities in older children, requiring more skin expansion, adding Z-plasty also in Rotation flap, in the same incision, as 2-in-1 incision. This was named as DOLARZ technique [7].

Third phase, still continuing, in grade 3 deformities, are mostly adolescents/ adults, requiring even more skin expansion, adding VY-plasty also in the same incision, as 3-in-1 incision, named DOLARZ-E,. E means extended, because it is not only VY-plasty, but extended too many other skin procedures used and described later in surgical steps. For still more expansion, fourth plastic surgery procedure i.e. fillet flap was also added in same incision, as 4-in1, for correcting World's First, Octopus Clubfoot (a new name), published $[1,8]$.

Third phase has been the most significant, opening floodgates with unending new research possibilities. An unbelievable revelation, Mother of all discoveries/ inventions, i.e. "Each Clubfoot is Different" also emerged in this phase. An equally incredible realization of their infallible, all-inclusive 4-in1 treatment protocol, also unfolded, which was stamped as a universal surgical concept, with an unparalleled Unity in Diversity. This firm assertion was a flashback on rediscovery of excellent correction in 2016 of Octopus Clubfoot [9], World's First and most extreme Clubfoot deformity in 18 years old female. If this can be corrected, then any and every other must also be correctible. This exotic patient had good media coverage: an interview by London UK media at Link: "dailymail. co.uk/health octopus clubfoot", https://www.hindustantimes. com/punjab/girl-with-eight-toes"; and Asian Age "Indian teen born with deformed foot can finally wear shoes www.asianage.com/ newsmakers/180617/indian-teen", viral on Google search.

\section{Material and Methods}

Evolution of 4-IN-1 Concept: This has been an evidence based research, since over 50 years. Firm evidence is derived from National and International plastic surgery literature [10-22] of cadaveric dissections, animal experiments and clinical experience. There is extensive vascular and lymphatic microcirculation, in the subfascial and suprafascial planes, with countless perforators arising from the deepest to most superficial planes. This was convincing enough for phased unification of the four plastic surgery procedures for MEGA skin expansion, as needed, in extreme deformities. One must remain outside in suprafascial plane, avoiding injury to perforators. Considering the site and size of gaps, distal based VY island flaps of various sizes, are designed in the same incision; in front, below or behind the medial malleolus. When old surgical scars are present, there may occasionally be marginal necrosis, without affecting the correction of deformity, due to extremely good vascular network of collaterals by perforators.

\section{Each clubfoot is different}

This is an evidence based new concept, mentioned briefly in SICOT Publication and with some more detail in author's book. More differently innovative thoughts have been added during the last about two years. Each clubfoot is different with countless variables, even in the same patient with increasing age. With endless variations, it will be more appropriate to call it clubfoot disease:

Classification: These differences are multifactorial, modified by static and dynamic influences, working throughout life. Dynamic factors work through foot/ leg muscles and physical activity, modifying static factors throughout life. Both these are primary in uncorrected virgin deformities. Secondary factors get added with conservative and surgical treatments. For better understanding, a comprehensive classification has been proposed:

A. At Birth: the usual four components of deformity, e.g. equinus, adduction, inversion and cavus are different in every case. Foot being a multi-arthrodial structure, there is coupling effects with unlimited combinations, at different ages.

a) Equinus: Traditionally equinus is defined as plantarflexion of foot at ankle only, while mid-foot plantar-flexion is called cavus and at toes it is called plantarflexion at distal foot. There is no mention of heel (calcaneal) plantar flexion. Equinus, being a plantar-flexion movement, it should include heel plantar-flexion, cavus and toes flexion also. Author viewed all these, as part of equinus for better surgical management. A comprehensive classification of Equinus should be allinclusive with five ascending hierarchic grades; EQ-1 to EQ5at ankle (EQ1), ankle+heel (EQ2), ankle+heel+cavus (EQ3), ankle+heel+cavus+toes (EQ4) and all fours + an old oversized, talus (EQ5) respectively [1,8] (Figure 1). All the five need correction and hence should be brought under one heading of positional morphology of foot. 


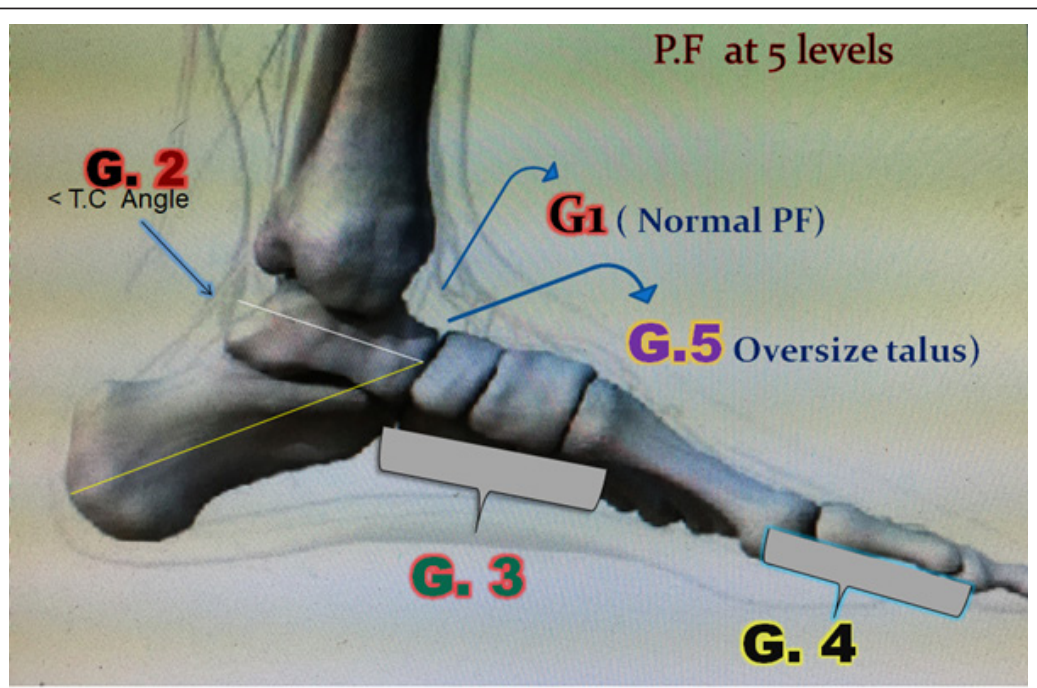

Figure 1: New perspective of equinus EQ1 to EQ5 as 5 hierarchic grades of plantar-flexion shown as (G1 - G5), highly important from treatment point of view.

b) Adduction; varyingly at tarsals, metatarsals and even toes, typically in first metatarsal, quite often in others, $2^{\text {nd }}$ to $5^{\text {th }}$ metatarsals.

c) Inversion; from a few degrees to 180 degrees.

d) Cock-up Deformity of big toe; often present in association with extreme medial cavus with fall of $1^{\text {st }}$ metatarsal head and hyperextended big toe, sometimes in other toes also.

B. Weight bearing effect: directly proportional to deforming elements.

C. Weight of the patient \& duration of weight bearingdirectly related.

D. Amount of physical activity- directly related.

E. Previous treatment: conservative and surgical. Deformity increases with more scars.
F. Effect of age- Deformity keeps increasing with age, making correction more difficult.

G. Congenital paralytic clubfeet- due to spina bifida, cerebral palsy etc.

H. Radiological variations in inter-osseous relationships in every case with age.

I. Other congenital defects in foot or other parts e.g. triple plus dislocation, hammer toe; shortening $4^{\text {th }}$ toe; coalitions; AGMC; polydactyly; hallux varus including varus in other digits as pandigitus varus. ; unusual congenital skin contractures; congenital constriction bands; genu varum, valgum and windswipe deformity; shortening and/ or hypoplasia of lower limb (Figure 2).

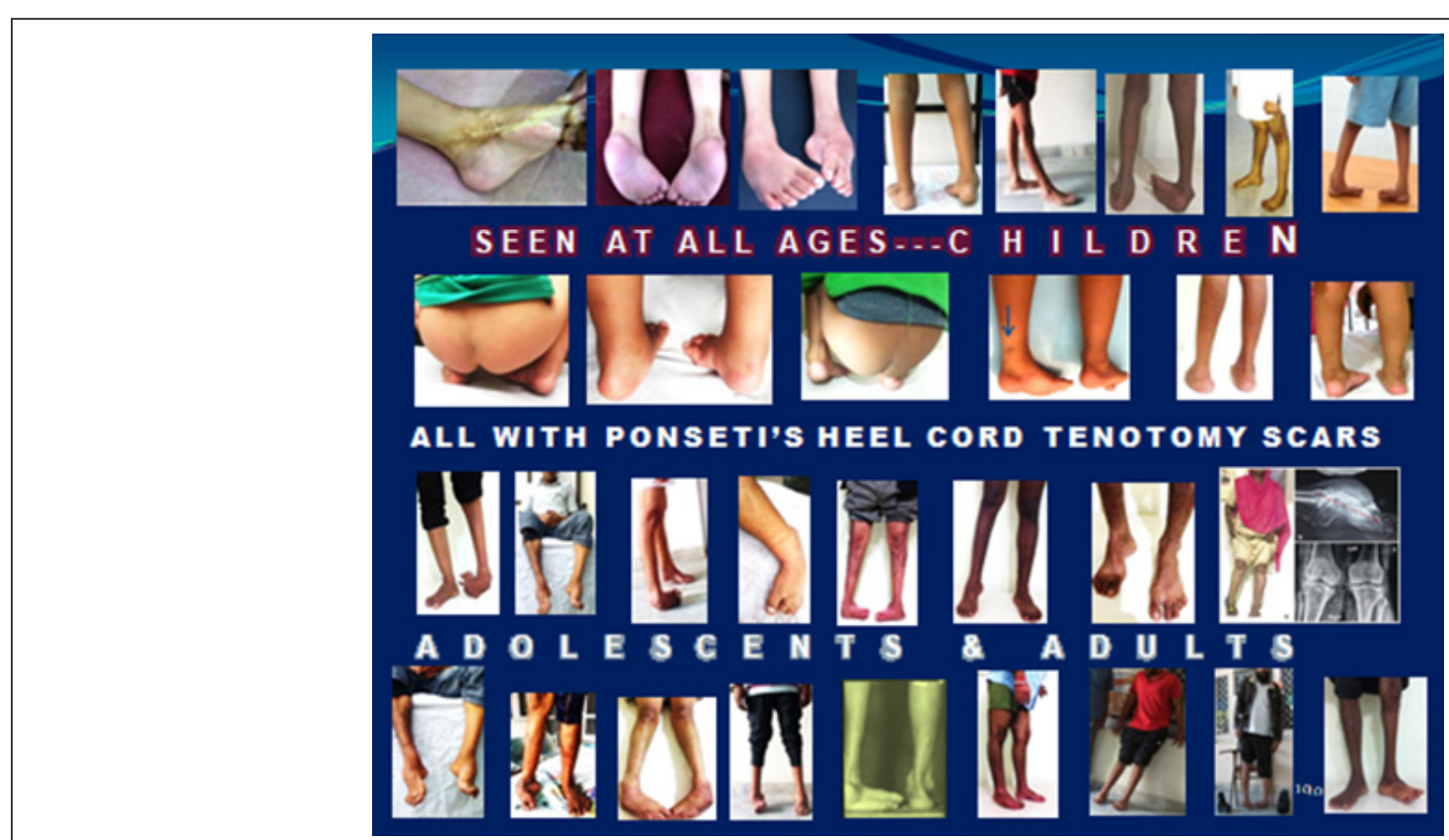

Figure 2: Each clubfoot is different- $1^{\text {st }}, 3^{\text {rd }}$ and $4^{\text {th }}$ rows showing that each is different from the others at all ages and $2^{\text {nd }}$ row shows Ponseti's heel Cord tenotomies with varied under-corrections and relapses. 
J. Heterogenous scars- primary alone since birth, each varying or complicated by one or more surgeries each varying. Surgical scars may be of heel cord tenotomies and others as: bow string, keloid, widely adherent to deeper tissues, making corrections impossible by other techniques, without fusion (Figure 3).
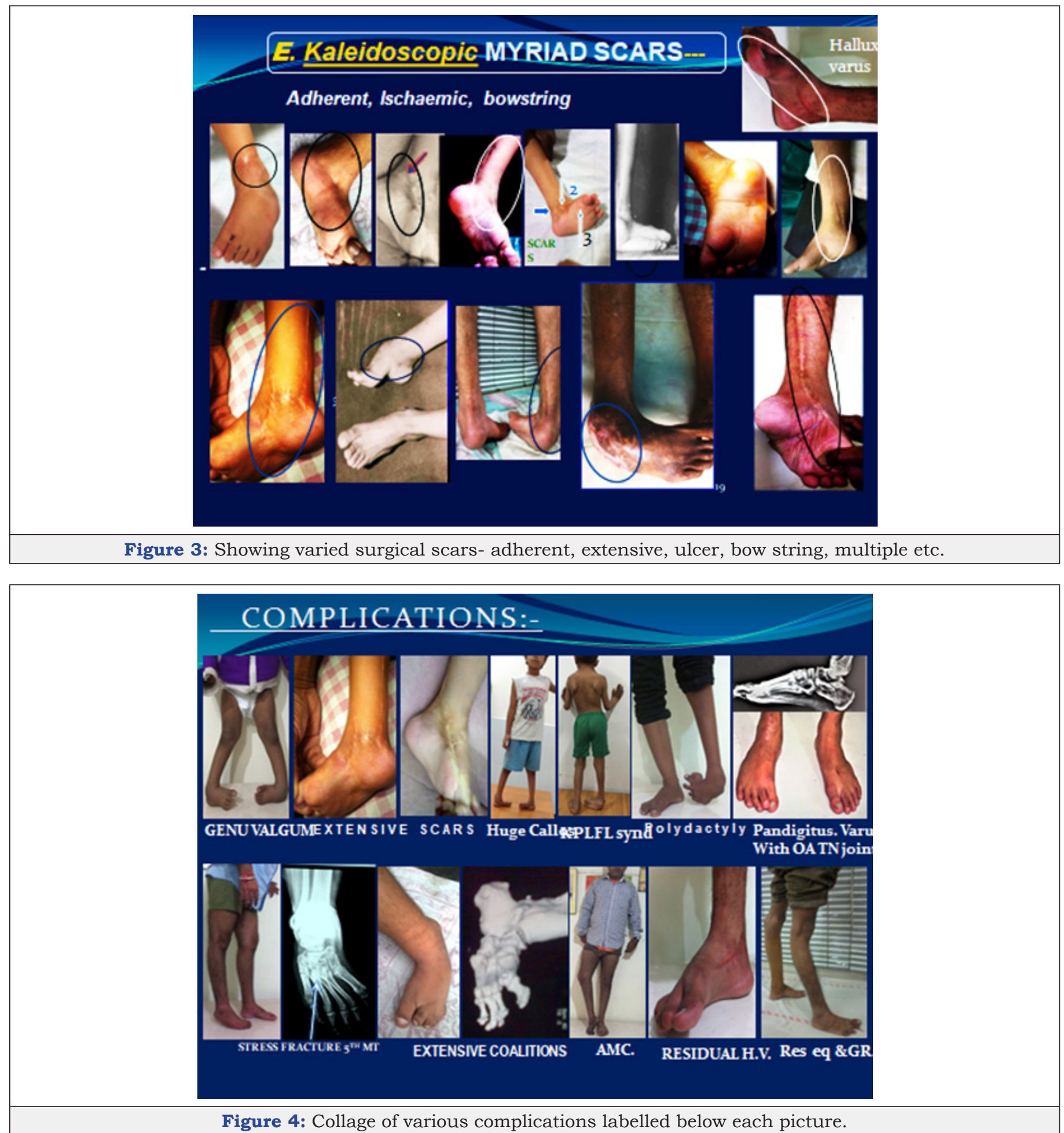

K. Complications: Early and delayed in scores (Figure 4).

a) Delayed milestones- Standing and walking age is delayed, directly proportional to severity of deformity, being more delayed in bilateral than unilateral deformities. b) Psycho-physico-socio-economic handicap: Awkward gait, low or no earning, marital problems of difficulty in match finding/after effects; Inferiority complex;

c) Painful walking due to inflamed Bursa, bunion, ulcer, painful plantar horn and limping. 
d) Trophic ulcers in paralytic clubfeet, with sensory loss, even chronic osteomyelitis in spina bifida.

e) Painful/unstable genu recurvatum.

f) Stress fracture $5^{\text {th }}$ metatarsal;

g) Early O.A in foot joints, knee, hip and spine;

h) Post trauma to leg: compartment syndrome, ischaemia and increased deformity; Crush injury in congenital clubfoot leading to unstable scar and increased deformity. All these have been seen by the author, treated and published $[1,8]$.

L. Post-operative clinical and radiological pictures. A good clinical correction can have radiological under-correction and vice versa.

M. Assessment protocols; with myriad variables, none of the popular assessment protocols could be applicable, unless the number of variables are within manageable limits as described by their proponents, which is unlikely. Patient satisfaction level is the best assessment criteris of surgical results.

N. Unforeseen and yet to be discovered in future, as each clubfoot is different.

Each deformity is a separate entity, requiring individual assessment and treatment planning, without a copy paste attitude.

\section{Surgical steps}

There are scores of surgical steps needed to correct extreme deformities. The usual surgical steps needed in a virgin uncorrected deformity are summed up as an extensive PMPDLR. However, other steps, needed sometimes, are also described, details varying in the wider trimorphic domain.

\section{Skin incision}

For Grade 1, it is a dorsolateral Rotation skin flap (DOLAR) as a single procedure, or as 2-in-1 i.e. DOLAR + Z-plasty on the medial side in Grade 2, (one or more Zs). In grade 3, VY-plasty is added (3-in-1) and occasionally fillet flap can be added as 4-in-1 [1] in any appropriate case. Many times decision has to be taken at the operation table itself. Besides the four plastic surgery procedures, many other skin procedures have been used, for correcting diverse rigid deformities, especially when old scars are excised and wound closure is not possible; these are: proximal relaxing incision, one or more lazy $\mathrm{z}$ or $\mathrm{v}$ to lengthen skin, Thiersch grafts for minor skin defects, double VY-plasties: either side by side or above and below, circular Z-plasties in CCBs in 4 sections; separate VY-plasties; a distal medial one to correct hallux varus, dorsal for hyperextended toes and plantar for hammer toes.

\section{Muscles \& tendons releases}

Abductor hallucis, Steindler's, tibialis posterior insertions; FHL \& FDP at Henry's knot releases, Z-lengthening of distal heel cord or proximal in case of distal scar, lengthening of tibialis anterior or extensor halluces longus in their contractures ; Ligaments/ capsules: spring ligament, CPC, Kendrick's TMT mobilization, ITC release, medial and plantar IT and TMT ligaments releases; Osseous: DL wedge resection from cuboid and if required, from cuneiforms, open wedge osteotomy of medial cuneiform with a bone graft from cuboid and talo-navicular reduction. Multiple $\mathrm{K}$-wires fixations are done to maintain correction. Wound closure is done after manipulating the flaps to get maximum skin chamber enlargement. Details of all deeper releases of muscles, tendons, ligaments, capsules and bones can be read in author's publications $[1,6,8]$. In under-corrected and relapsed cases with adherent scars of earlier surgeries, conventional surgery is not possible, due to dense adhesions and obscurity of deeper structures. However, besides excising the scars, the basic concept of PMPDLR remains the same, remaining close to bones, avoiding injury to neurovascular structures and achieving a good correction.

\section{Results and Conclusion}

In diverse situations, our aim is to achieve the best possible correction without arthrodesis by innovative modifications, many times decided at the operation table. The rational concept of unified 3 and 4-in-1 skin expanding techniques will always make it possible, in spite of, EACH CLUBFOOT BEING DIFFERENT. This has been very well proved, in variety of cases in earlier publications $[1,6,8]$ and many more recent ones in Table 1 in this article. Learning the techniques is not difficult form various publications of author and youtube videos at author's channel "Patiala Clubfoot Foundation". These are more cost effective than others and giving far better results, more satisfying to patients on long term. Immediate surgical operative costs are much less, besides the lifelong gain in psychophysico-socio-economics of the patients (Figure $5 \& 6$ ).

Table 1: Showing variety of cases, each different.

\begin{tabular}{|c|c|c|c|c|}
\hline Case. NO & $\begin{array}{c}\text { Name, Age, Sex, Side, Prev tt } \\
\text { Fig, no }\end{array}$ & 0/E; Patho-Anatomy Grade & Surgical Correction & Result as pt satisfac, FU \\
\hline 1 & $\begin{array}{c}\mathrm{T}, 1 \frac{1}{2} \mathrm{YM}, \mathrm{Rt} \text {, Pcasts } \mathrm{HCT}^{3} \text { in } 4 \\
\text { mths, Figure } 5 \mathrm{i} \text {-iv }\end{array}$ & $\begin{array}{c}\text { HCT }^{3} \text {, skin scars, Rigid EQ3, relap }{ }^{3} \text {, } \\
\text {.Gr2, HC adhes }\end{array}$ & $\begin{array}{l}\text { DOLAR+Z, HC freed ,Prox.TALZ, } \\
\text { PMPDLR,K-wires, }\end{array}$ & Excellent at $9 \mathrm{mths} \mathrm{FU}$ \\
\hline 2 & $\begin{array}{c}\text { Roh.21/2YM, Rt, Pcasts, } \text { HCT }^{3} \text { in } \\
1 \frac{1}{2} \mathrm{y} \text {, Figure } 5 \text { v-ix }\end{array}$ & $\begin{array}{c}\text { HCT }^{3} \text { skin scars, Rigid EQ3, relap } \\
\text { Gr3, CUBT, HC adhes }\end{array}$ & $\begin{array}{l}\text { DOLARZ, PMPDLR, gap in HC, } \\
\text { FHL-FTG, K-wires, DLWR, K-wires }\end{array}$ & Excellent at $21 / 2 \mathrm{Y} \mathrm{FU}$ \\
\hline
\end{tabular}




\begin{tabular}{|c|c|c|c|c|}
\hline 3 & $\begin{array}{l}\text { IK21/2YM, Lt., Pcasts HCT } \mathrm{HC}^{1} \text { at } 1 \mathrm{Y}^{\prime \prime} \\
\text { Figure } 5 \mathrm{x} \text {-xiv }\end{array}$ & $\begin{array}{l}\text { HCT skin scar, Relap EQ3, lower } \\
\text { part HC adhes, Gr2, }\end{array}$ & $\begin{array}{c}\text { DOLAR flap,PMPLR, TA scar and } \\
\text { Prox, TAL }\end{array}$ & Excellent correction, $1 \mathrm{Y} \mathrm{FU}$ \\
\hline 4 & $\begin{array}{l}\text { LPK, } 6 Y, F, \text { Rt, CCBs, cong amp toes, } \\
\text { Pcasts } \text { HCT }^{1} 2 \frac{1}{2} \mathrm{Y} \text {, walks on post/ } \\
\text { lat side sole. Figure } 5 \mathrm{xv}-\mathrm{xx}\end{array}$ & $\begin{array}{l}\text { HCT skin scar, CV , FDF def, Callos } \\
\text { midfoot, hour-glass CCB leg }\end{array}$ & $\begin{array}{l}\text { DOLAR+VY, PMDPLR: ACA, Tib } \\
\text { ALZ, DLWR, HC gap closed by prox } \\
\text { ZTAL. }\end{array}$ & $\begin{array}{l}\text { Excellent callos gone. Gait } \\
\text { normal, } 23 / 4 \mathrm{Y} \text { FU }\end{array}$ \\
\hline 5 & $\begin{array}{l}\text { AVS, 5Y, M, BL, Pcasts } \mathrm{HCT}^{1} \text { at } 3 \\
\text { mths, Lt OK, Rt PMR } 1 Y \text {. }\end{array}$ & $\begin{array}{l}\text { HCT/ PMR scars, EQ4: HCadhes } \\
\text { ECV Gr3, relap². }\end{array}$ & $\begin{array}{l}\text { DOLAR+Z+VY, ZTAL PMPLDR. } \\
\text { DLWR. KWs }\end{array}$ & Excellent at $2 \mathrm{Y} \mathrm{FU}$ \\
\hline 6 & $\begin{array}{l}\text { ADS, } 121 / 2 Y, M, B L, \text { Pcasts } \mathrm{HCT}^{1} 1 \mathrm{Y}, \\
\text { Illizarov2Y,. Figure } 5 \mathrm{xxi}-\mathrm{xxv}\end{array}$ & $\begin{array}{l}\text { HCT skin scars BL, Gr3, EQ4 B/L, } \\
\text { GR/GV, all DFs zero, relap², Post. } \\
\text { Calc. humps, Very rigid. }\end{array}$ & $\begin{array}{l}\text { DOLAR+Z+VY: BL, Lt: Jul18, } \\
\text { RtJan19. PMPDLR, DLWR and } \\
\text { bony humps calc excised. }\end{array}$ & $\begin{array}{c}\text { Excellent, Lt at } 1 \frac{1}{2} \mathrm{Y} \mathrm{FU}, \mathrm{RT} \\
1 \mathrm{Y} \mathrm{FU} .\end{array}$ \\
\hline 7 & $\begin{array}{c}\text { RK, 61/2Y, F, BL, Pcasts/BL/HCT } 313 \\
\text { mths, Rt OK. Lt HCT at } 3 y, \text { relap }^{2} \text {, } \\
\text { PMR. }\end{array}$ & $\begin{array}{l}\text { Lt adherent TA PMR, } \mathrm{HCT}^{2} \text { scars, } \\
\text { relap }{ }^{3} \text { Rigid EQ3, ECV, very high } \\
\text { dome. }\end{array}$ & $\begin{array}{c}\text { DOLAR+Z+VY, PMPDLR, HC freed, } \\
\text { ZTAL, DLWR, KWs }\end{array}$ & Excellent at $1 \mathrm{Y} \mathrm{FU}$ \\
\hline 8 & $\begin{array}{c}\text { Ansh, 11/2y, M, BL, pcasts Dorsum } \\
\text { walk }\end{array}$ & Rigid Gr 2 def. EQ3- & $\begin{array}{l}\text { DOLARZ, BL, PMPDLR Lt: Jan17, } \\
\text { RtSep17 }\end{array}$ & Excellent, 3Y Lt 21/4YRt \\
\hline 9 & $\begin{array}{l}\text { AS, } 15 Y M, B L, \text { Rt }>\text { Lt Scars }{ }^{3} \text {, } \\
\text { relapse waddles on MT heads. } \\
\text { Both feet reqd } 2 \text { stage surgeries }\end{array}$ & $\begin{array}{l}\text { Rigid Gr3, EQ4 up to toes, } \\
\text { extensive adherent scars BL, Rt } \\
\text { more, X- IT,TMT IORD }\end{array}$ & $\begin{array}{l}\text { DOLAR+2Zs, } \operatorname{surg}^{2} \text { BL,PMPDLR, } \\
\text { Extra DLWR, no fusion Lt Rt } \\
\text { DFCVY } 4^{\text {th }} \text { toe and Triple fusion }\end{array}$ & Excellent FU Lt 11/4Y, Rt $1 Y$ \\
\hline 10 & MjtK12/5YFC, BL, EQ3, Gr3 & $\begin{array}{c}\text { BL Rigid Gr3, EQ3, Stand on lat. } \\
\text { dorsum, }\end{array}$ & $\begin{array}{c}\text { DOLAR+ Z+ VY Rt at 12/5Y. } \\
\text { DOLAR+Z Lt 22/5Y, PMPDLR, KWs }\end{array}$ & $\begin{array}{l}\text { Excellent FU Lt 2Y, Rt } 10 \\
\text { mths }\end{array}$ \\
\hline 11 & $\begin{array}{c}\text { Rdm10YM, BL, Both operated at } 2 \\
\text { yrs by DOLAR+Z+VY. Rt excellent, } \\
\text { Lt relapsed }\end{array}$ & $\begin{array}{l}\text { Rt corrected. LT rigid Varus and } \\
\text { EQ4, Gr3, lat border gait. }\end{array}$ & $\begin{array}{c}\text { Excision scars, Revision } \\
\text { DOLAR+Z+VY, DLWR K-wires }\end{array}$ & $\begin{array}{l}\text { Excellent Lt at } 9 \mathrm{mths} \text { and } \\
\mathrm{Rt} \text { foot at } 9 \mathrm{Y} \text {. }\end{array}$ \\
\hline 12 & $\begin{array}{l}\text { Ansl.24YMRt, surg² at } 8 \text { Mths/4Y, } \\
\text { relap2, Operated June } 2019\end{array}$ & $\begin{array}{l}\text { PMR Scars, Rigid Gr3, EQ4, OATNJt } \\
\text { longer walk painful, Ugly looks } \\
\text { Pan-digitus-varus.. }\end{array}$ & $\begin{array}{l}\text { DOLARZ, PMPDLR, FCVYGT/ MP } \\
\text { Jt, KWs, FDBTR } 4^{\text {th }} \text { toe and MKWs. }\end{array}$ & $\begin{array}{l}\text { Excellent } 8 \text { mths FU. Varus } \\
\text { toes much less. }\end{array}$ \\
\hline 13 & $\begin{array}{c}\text { AbhS7MC, Lt, uncorrected, walks } \\
\text { lat border (ant). Figure } 5 \text { xxvi- } \\
\neg \times x \times i\end{array}$ & $\begin{array}{l}\text { Gr3, EQ4, very rigid, double callos. } \\
\text { Gross wasting leg, thigh, }\end{array}$ & $\begin{array}{c}\text { DOLAR+z+VY, PMDPLR, } 2 \text { prox. RI } \\
\text { PTSGs.K-wires. }\end{array}$ & Excellent, FU 5 mths. \\
\hline 14 & SD1YMC, BL, not walking yet & $\begin{array}{l}\text { Gr3, EQ3, rigid with cong amp. } \\
\text { tips toes, CCBs (deep Rt leg, }\end{array}$ & $\begin{array}{l}\text { BL DOLAR and PMDPLR. with Rt } \\
\text { as } 1^{\text {st }} \text { stage Circ Zs, }\end{array}$ & $\begin{array}{l}\text { Excellent Lt partial Rt } 9 \\
\text { Mths FU. }\end{array}$ \\
\hline
\end{tabular}

Abbreviations of Table 1: Adhesions (Adhes), Amputation (amp), Anterior capsulotomy ankle (ACA), Bilateral (BL), Calcaneum (Calc), Callosity numbers as superscript (Callos ${ }^{2}$ ), Circumferential (Circ), Child (C), Congenital amputation (Cong amp), Congenital Constriction bands (CCBs), Cock-up big toe (CUBT) Calcaneo-varus (CV), Dorsiflexors (DFs); Dorsolateral (DL), Equino-cavo-varus (ECV), Equinus1-5 (EQ1-5), Fasciocutaneous VY-Plasty Great Toe (FCVYGT); Fixed dorsiflexion deformity(FDFDef), Female (F), Follow up (FU), Flexion deformity (FD), Figure (Fig), Female (F), First (1 $\left.{ }^{\text {st }}\right)$, Flexion deformity (FD), Flexor digitorum Brevis Tendon Release (FDBTR), Free Tendon Grafting (FTG), Flexor Hallucis Longus (FHL), Great toe (GT), Grade (Gr), Heel Cord adhesions (HC adhes); Heel Cord Tenotomies number shown as superscript (HCT2), Hallux varus (HV), Increased Inc), Intertarsal (IT), Left (Lt), Right (Rt), Metatarsals (MT), Male (M), Year (Y), Months (mths), Muscle power gr 0-5 dorsiflexors (DFs
Zero), Operation (Op), Osteoarthritis Talonavicular joint (OATNJt), Plantar-flexion (PF), Postero-medial-dorsalplantar- lateral release (PMDPLR), Partial thickness skin graft, (PTSG), Ponseti casts (Pcasts), Patient (Pt), Proximal Relaxing Incisions (Prox.RI), Proximal Tendoachilles Lengthening Z-plasty (ProxTALZ); Relapse numbers shown by superscript (Relap2), Residual equinus (RE), Previous treatment Prev tt); Resection (resect), Relaxing incisions (RIs), Required Reqd), Surgery (Surg), satisfaction (satisfac); Serial number (S. No), Second (2nd), Talo-navicular (TN), Scars of number of earlier surgeries shown as superscript $\left(\right.$ Scars $\left.{ }^{2}\right)$, Tendoachilles (TA)Tibialis anterior Z-lengthening TibALZ); Tarso-metatarsal (TMT), Two stage surgergies (Surg2), X-ray Interosseous Relationship disturbed (X-IORD), Dorsolateral Wedge resection (DLWR), Year (Y), $Z$-plasty or ies $(Z$ or $Z s), Z$ Lengthening of Tendoachilles (ZTAL). 


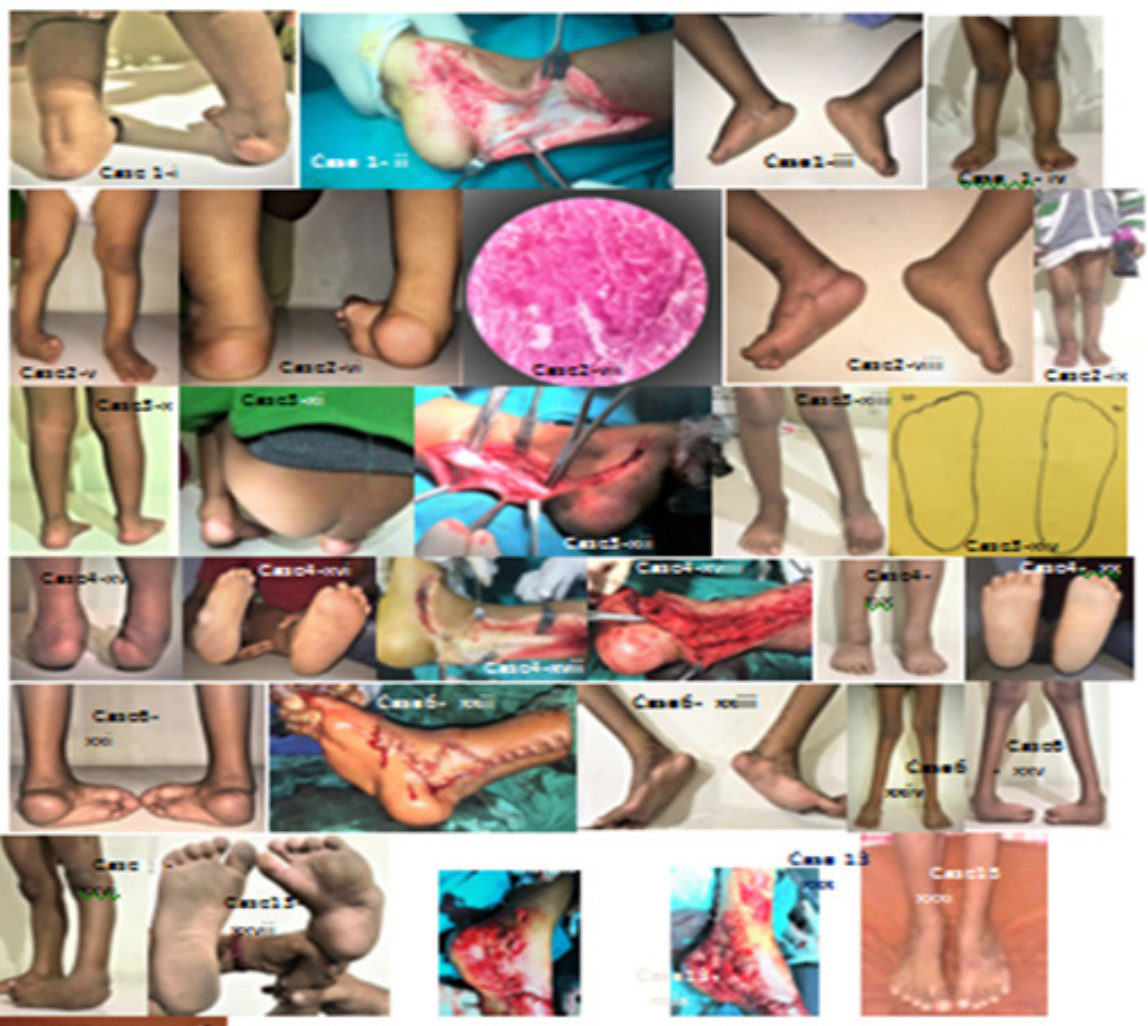

Figure 5(Table 1): Case-1(i-iv) $\mathrm{HCT}^{3}$ scars, scarred TA and corrected deformity; Case-2(v-ix) Stands lateral border, $\mathrm{HCT}^{1}$ scar, irregular scar collagen, Prox ZTAL and correction; Case-3(x-xiv) HCT ${ }^{1}$, EQ3, scar TA, Prox ZTAL, corrected def and prints; Case-4(xv-Xx) CCBs, $\mathrm{HCT}^{1}$, callos, scarred TA with gap below, Prox ZTAL, corrected def and healed callos; Case-6(xxi-xxv) HCT ${ }^{1}$ BL, EQ4, BL DOLARZ-E, Corrected Defs BL; Case-13(xxvi-xxxi) EQ4, Callos ${ }^{2}$, DOLARZ-E and 2 RIs with 3 split skin grafts patches, corrected def with all scars well healed.

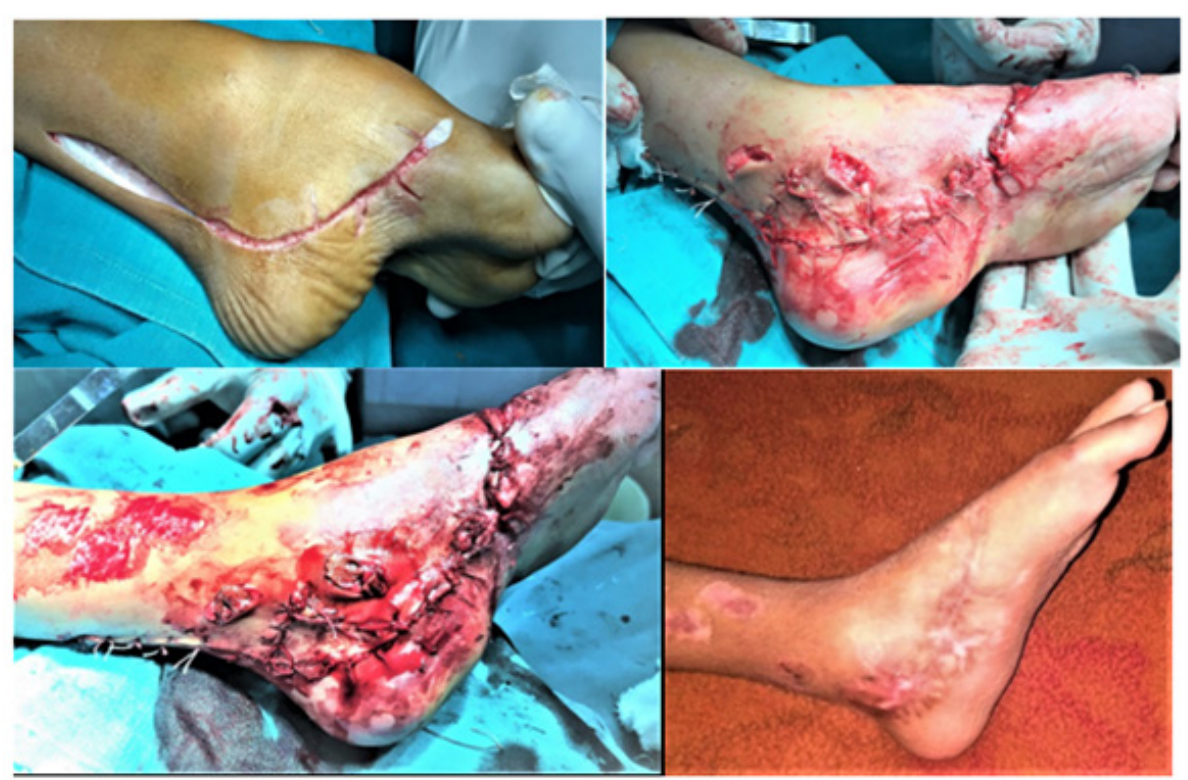

Figure 6: Magnified views of case 13 table1, \#-in-1 + 3 Thiersch grafts on relaxing incisions to Cover the raw areas and final healing, normally walking at 5 months follow up.4eview 


\section{Discussion}

Extreme clubfoot deformities have been a life time research area of author, pursued in three phases, since over 50 years. It can very well be compared with the story of famous Chinese bamboo tree, establishing strong root system for many years before it sprouts up [23]. Similarly, this research took many years (about 15 to get firmly rooted) and rationalized for execution, before the experimental and three phased (grade 1-3) clinical studies.

It has emerged, as a need based research, from highly prevalent under-corrections/ relapses of over 95\%, in extreme deformities (a new generic name given by author), reported in literature with scores of confusing brand names of neglected deformities treated by contemporary surgical techniques, including the popular ones.

"Each Clubfoot is Different" is the SOUL of this research, a powerful Mother innovation, with potential for changing Global thinking about clubfoot. This was an afterthought in the third phase of this research, an unprecedented powerful Grassroots discovery, now a grown up tree with its umbrella of countless branches and leaves, each different, yet all connected with the roots. So are the countless, varied deformities getting unified in their all-inclusive surgical concept. This discovery, with potential for changing global thinking about clubfoot, emerged from highly prevalent under-corrections/relapses of over 95\%, reported in literature, with scores of confusing names. The contemporary surgical techniques, including the popular ones: Ponseti's and Illizarov's, do not succeed in extreme deformities. Ponseti technique succeeds in mild and moderate deformities, if his guidelines of right age, type of deformity, casting technique, bracing and follow up are strictly followed,. Being labour intensive, these are neglected by care givers as well as recipients, with numerous pitfalls, reported by Ponseti himself in details in their own articles [5,6], in author's book and many others. In spite of Ponseti's advice against using in more rigid/ severe deformities, vast majority are still doing and failing. First eight cases in Table 1, in this article, are testimony to this assertion. Heel cord tenotomy does more harm than good. It leads to dull white irregular collagen in the gap with adhesions all round, with persisting under-corrected varus and later on relapses (Table 1, Figure 5; cases $(1-4,6,15)$ ). Bones grow, but scars do not and hence increasing relapses with age, emphatically asserted by Ponseti himself, and quoted by author [8].

Heterogeneous skin contractures, primary alone or with surgical scars, have always remained neglected, with imperative need for correction. The cramped cell-like room has to be enlarged in 3D, giving proper head and leg space to each occupant and accommodate all in orderly position. This became realty with the invention of triple or even quadruple surgical mega skin expanding incision, each in 3D, as FUSION 3 or 4-in-1. The four plastic surgery procedures of Rotation flap, Z-plasty, VY-plasty and Fillet flap are commonly used as single procedures. Author merged all four procedures into an unprecedented single incision for maximum fascio-cutaneous chamber expansion. It is abundantly, evidence based and time tested too. This was in three phases, as need based procedures, because, with spreading awareness, more and still more severe/rigid deformities presenting for treatment, requiring increasing skin expansion. The extensive deeper soft tissue and osseous releases get reattached in the foot in the corrected position and stabilize. With increasing grade of deformity, they are used as single, 2-in-1, 3-in-1 or 4-in-1, without any bony fusion in vast majority, getting a longer, good looking, flexible and better functioning foot on long term than by other techniques. In still more rigid deformities, some other skin procedures, as detailed in surgical steps, may also be used; as in case No. 13 Table 1, when wound closure was not possible 2 relaxing incisions were given and raw areas were covered with Thiersh grafts from adjacent part of lower leg with uneventful wound healing and patient normal at 5 months follow up (Figure 6. I-IV enlarged views)

After treating the world's First, most rigid/ severest deformity, OCTOPUS CLUBFOOT in 2016, these surgical techniques, of Fusion 4-in-1, have now become an imprinted all-inclusive surgical concept, correcting any and every deformity. Learning this evidence based concept is not difficult for clubfoot enthusiasts. This surgical concept is like a Master Key opening all locks.

Working out the economics, WHO documents of 2004 and 2008 [23], on congenital anomalies including clubfoot, quote a very high loss of DALYs of 25.3-38.8 million globally. As regards GBD, congenital anomalies, including clubfoot, ranked as $17^{\text {th }}$ cause of GBD. Feet are an organ of locomotion for daily living and earn livelihood. Extreme clubfooted, especially bilateral, will earn less or nothing, adding to GBD. These surgical techniques are not costlier than others. Global clubfoot community in LMICs, with over $80 \%$ population, is looking towards us expectantly for a better deal and giving them a full meal with lesser cost, rather than costlier half meal. They are not difficult to learn, giving far better results with ROZY feet having pleasing looks improving earning capacity for entire life, boosting psycho-physico-socio-economics of patients [24]. Foot gets stabilized in about 6 months.

To conclude, this is the Mother of all clubfoot inventions, emanating from the earlier publications on extreme clubfoot deformities, unifying the beads in a Rosary or pearls in a necklace "Each Clubfoot is Different" is a remarkable discovery, even more is its incredible/ unsurpassed "Unity in Diversity" manifested by their treatment protocol of 4 -in-1 concept. In a broader sense, it is just like: Each human being is different, yet human race is one. The Global clubfoot community in LMICs, with over $80 \%$ population, is looking towards us expectantly to fulfill their dreams.

\section{Acknowledgement}

In the texts and many parts all the 5 Figures, have been duly quoted/printed/ adapted by kind Courtesy:

1. Taylor \& Francis group (CRS Press) adopted from author's own book Clubfoot- A comprehensive approach past, present \& future: Ist edition, by Dr. R L Mittal. Dec.2018. ISBN9781138083738)

2. Springer Nature and Copyright clearance centre of RightsLink. From author's own published article; Int Orthop 
(SICOT) 1987; 11(3):189-92. PMID: 3623754; DOI: https://doi. org/10.1007/BF00271446.

\section{References}

1. Mittal RL (2018) Trimorphic extreme clubfoot deformities and their management by triple surgical skin expanders- DOLAR, DOLARZ and DOLARZ-E (evidence based mega corrections without arthrodesis). International Orthopaedics 42(6): 1297-1306.

2. Tarraf YN, Carroll NC (1992) Analysis of the components of residual deformity in clubfeet presenting for reoperation. J Paediatr Orthop Apr 12(2): 207-216.

3. Ponseti IV, Smoley EN (2009) The classic congenital club foot: The results of treatment. Clin Orthop Relat Res 467(5): 1133-1145.

4. Staheli L, Ignacio P (2009) Clubfoot: Ponseti management manual. ( $3^{\text {rd }}$ edn), pp. 1-32.

5. Mittal RL, Makhni SS, Sidhu GS (1981) Morbid anatomy of congenital clubfoot. Ind J Orthop 15: 129-135.

6. Mittal RL (1987) The surgical management of resistant clubfoot by rotation skin flap and extensive soft tissue release. Int Orthop 11(3): 189-192.

7. Mittal RL (2014) Obstinate clubfoot with triple plus dislocation. J Foot Ankle Surg 1(2): $72-77$.

8. Mittal RL (2018) CLUBFOOT-A comprehensive approach (past, present and future). ( $\left.1^{\text {st }} \mathrm{edn}\right), \mathrm{pp} \cdot 1-98$

9. Mittal RL (2019) Octopus clubfoot rediscovered - World's first exotic case - A neglected, triple axes rotational, grade 3 extreme deformity: Corrected by, unparalleled, 4-In-1 mega surgical skin expansion from crooked to ROZY foot. Ortho Res Online J 6(1): 550-553.

10. Bhattacharya V (2016) Experimental and clinical evidence based rationality of incorporation of deep fascia in tissue transfer for reconstructive surgery. Ann Natl Acad Med Sci 52(4): 222-231.

11. Ponten B (1981) The fasciocutaneous flap: its use in soft tissue defects of lower leg. BJPS 34(2): 215-220.
12. Cormack GG, Lamberty BGH (1986) The fasciocutaneous system of vessels. The arterial anatomy of skin flap. Churchill Livingstone, UK.

13. Taylor GI, Palmer JH (1987) The vascular territories (angiosomes) of the body: Experimental study and clinical applications. BJPS 40: 113-141.

14. Bhattacharya V, Deshpande SB, Watts RK (2005) Measurement of perfusion pressure perforators and its correlation with their internal diameter. BJPS 58: 759-764.

15. Bhattacharya V, Watts RK, Reddy GR (2005) Live demonstration of microcirculation in the deep fascia and its implication. Plast Reconstr Surg 115(2): 458-463.

16. Bhattacharya V, Goyal S (2006) A dye study in fresh cadavers to outline retrograde flaps of the lower limb and to examine clinical implications. Europ Journ of Plast Surg 28: 458-463.

17. Bhattachatya V, Goyal S, Jain P, Singh NS (2006) Angiographic evaluation of fasciocutaneous flaps. Int Surgery 91: 326-331.

18. Bhattacharya V, Reddy GR, Goyal S, Kumar U (2007) Skeletonised retrograde distal perforator island fasciocutaneous flaps for leg and foot defects. J Plast ReconstrAesthet Surg 60(8): 892-897.

19. Bhattacharya V, Barooah PS, Nag TC (2010) Detail microscopic analysis of deep fasciao flower limb and its surgical implication. IJPS 43: 135-140.

20. Bhattacharya V, Choudhuri GR, Mishra B, Kumar U (2011) Demonstration of live lymphatic circulation in the deep fascia and its implication. Europ Journ of Plastic Surg 34(2): 99-102.

21. Bhattacharya V, Agrawal NK, Chaudhury GR (2012) CT Angiographic evaluation of perforators in the lower limb and their reconstructive implication. IJPS 45(3): 494-497.

22. Mittal RL (2019) Feet also need cosmetic/ plastic surgery for good looks (A new perspective) world's first, graded, mega skin expansion by fusion 4-In-1, correcting, all-inclusive, extreme clubfoot deformities-A game changer. J Dermatol \& Skin Sci 1(1): 8-17.

23. https://www.mattmorris.com/how-success-is-like-a-chinesebamboo-tree/

24. World Health Organization (2008) The global burden of disease: 2004 update. WHO Press, Geneva, Switzerland. 